Pacific Journal of Mathematic 


\title{
SOME CONTINUITY PROPERTIES OF THE SCHNIRELMANN DENSITY II
}

\author{
R. L. DUNCAN
}

Let $S$ denote the set of all infinite increasing sequences of positive integers. For all $A \cong\left\{a_{n}\right\}$ and $B=\left\{b_{n}\right\}$ in $S$ define the metric $\rho(A, B)=0$ if $A=B$; i.e., if $a_{n}=b_{n}$ for all $n$ and $\rho(A, B)=1 / k$ otherwise, where $k$ is the smallest value of $n$ for which $a_{n} \neq b_{n}$. The main object of this note is to show that the set of points of continuity of the Schnirelmann density $d(A)$ is a residual set and that this is the best possible result of this type.

The space $S$ and some of the properties of densities defined on it have been discussed previously [2,3,4]. In particular, it has been shown that the set of points of continuity of $d(A)$ is the set of all points having density zero. Let $L_{a}=\{A \in S \mid d(A)=a\}(0 \leqq a \leqq 1)$ denote the level sets of $d(A)$ and define $M_{a}=\{A \in S \mid d(A) \geqq a\}$. Then $\bar{L}_{a}=M_{a}$ so that $M_{a}$ is closed and $L_{a}$ is dense in $M_{a}$ [4]. These results are required in the sequel. A brief and lucid account of all other necessary topological results is given in [1].

THEOREM 1. The family of all sets of the form $S(m, n)=$ $\left\{A \in S \mid a_{n}=m\right\}$ is a sub-basis for the topology of $S$.

Proof. If $A \in S(m, n)$ and $B \notin S(m, n)$, then $\rho(A, B) \geqq 1 / n$. Hence $S-S(m, n)$ is closed and $S(m, n)$ is open. Also, the spheres $S_{\varepsilon}(A)=$ $\{B \in S \mid \rho(A, B)<\varepsilon\}, 0<\varepsilon \leqq 1$, constitute a basis for $S$ and the desired result follows since

$$
S_{\varepsilon}(A)=\bigcap_{n=1}^{[1 / \varepsilon]} S\left(a_{n}, n\right)
$$

Corollary. S has a countable basis.

CoRollary. $S$ is separable.

It is also clear that $S$ is a subspace of $\mathrm{X}_{n=1}^{\infty} P_{n}$, where $P_{n}$ is the set of all positive integers with the discrete topology for each $n$.

THEOREM 2. $S$ is complete.

Proof. Let $A_{n}=\left\{a_{n, 2}\right\}_{\nu=1}^{\infty}$ and suppose that $\left\{A_{n}\right\}$ is a Cauchy sequence in $S$. Also, let $n_{k}$ be the smallest positive integer such that 
$\rho\left(A_{m}, A_{n}\right)<1 / k$ for all $m, n \geqq n_{k}$ and define $A=\left\{a_{n_{k}, k}\right\}_{k=1}^{\infty}$. Since all of the $A_{n}$ 's have the same first $k$ terms for $n \geqq n_{k}$, it is clear that $A \in S$ and $\rho\left(A_{n}, A\right)<1 / k$ for all $n \geqq n_{k}$. Hence $\lim _{n \rightarrow \infty} \rho\left(A_{n}, A\right)=0$ and $S$ is complete.

The following corollaries are a consequence of the Baire category theorem and the fact that $M_{a}$ is a closed subset of $S$.

CoRollary. $M_{a}$ is complete.

CoRollary. $M_{a}$ is a set of the second category in itself.

The following result would be of no interest for those values of $a$ for which the second of the above corollararies fails to hold.

Theorem 3. $L_{a}$ is residual in $M_{a}$.

Proof. $\quad M_{a}-L_{a}=\bigcup_{k=1}^{\infty} M_{a+1 / k}$. Since $\bar{L}_{a}=M_{a}, L_{a}$ is dense in $M_{a}$ and, since $M_{a+1 / k} \subset M_{a}, L_{a}$ is dense in $M_{a+1 / k}$. Also, since $M_{a+1 / k}$ is closed, $M_{a+1 / k}$ is nowhere dense in $M_{a}$ and $M_{a}-L_{a}$ is a set of the first category in $M_{a}$.

Since the set of points of continuity of $d(A)$ is $L_{0}$ and $M_{0}=S$, the following result ensues.

COROLlaRY. The set of points of continuity of $d(A)$ is residual in $S$.

The following theorem shows that the above corollary is a best possible result in the following sense. In the true statement, $S-L_{0}$ is a countable union of nowhere dense sets, the word countable can not be replaced by finite.

THEOREM 4. $\overline{M_{a}-L_{a}}$ is open if and only if $a=0$ or 1.

Proof. $\overline{M_{1}-L_{1}}$ is the empty set and hence open. Also, it is easily seen that $\bar{M}_{0}-L_{0}=S(1,1)$ in the notation of Theorem 1 and hence open.

Suppose that $\overline{M_{a}-L_{a}}$ is open for $a>0$. Then $\overline{M_{a}-L_{a}} \subset M_{a}$, since $M_{a}$ is closed, and it follows that $L_{0} \subset S-\overline{M_{a}-L_{a}}$. Since $\bar{L}_{0}=S$ and $S-\overline{M_{a}-L_{a}}$ is closed, we have $S-\overline{M_{a}-L_{a}}=S$ and $\overline{M_{a}-L_{a}}$ is the empty set. Thus $a=1$ and the proof is complete.

The following result is included in the preceding proof. 
COROLLARY. The support of $d(A)$ is the set of all sequences with first term one.

The final result concerns the asymptotic density

$$
\delta(A)=\lim \inf A(k) / k,
$$

where $A(k)$ denotes the number of elements of $A$ which do not exceed $k$.

Theorem 5. $\delta(A)$ is a function of Baire class two.

Proof. Let $\delta_{n}(A)=\inf _{k \geqq n} A(k) / k$. Then $\delta_{n}(A)$ is a function of Baire class one [4, Th. 3]. Also, $\delta(A)=\lim _{n \rightarrow \infty} \delta_{n}(A)$. Now $\delta(A)$ is obviously everywhere discontinuous on $S$. Suppose $\delta(A)$ is a function of Baire class one. Then the set of points of discontinuity of $\delta(A)$ is a set of the first category [5, Th. 36]. But $S$ is a set of the second category and the desired result follows.

\section{REFERENCES}

1. J. D. Baum, Elements of point set topology, Prentice-Hall, 1964.

2. R. L. Duncan, A topology for sequences of integers I, Amer. Math. Monthly 66, (1959), 34-39.

3. - A topology for sequences of integers II, Amer. Math. Monthly 67 (1960), 537-539.

4. - Some continuity properties of the Schnirelmann density, Pacific J. Math. 26 (1968), 57-58.

5. L. M. Graves, The theory of functions of real variables, Mc-Graw Hill, 1956.

Received February 6, 1968, and in revised form July 15, 1969.

King of Prussia Graduate Center

The Pennsylvania State University 



\section{PACIFIC JOURNAL OF MATHEMATICS}

\section{EDITORS}

\author{
H. SAMELSON \\ Stanford University \\ Stanford, California 94305 \\ Richard Pierce \\ University of Washington \\ Seattle, Washington 98105
}

J. DUGUNDJI

Department of Mathematics

University of Southern California

Los Angeles, California 90007

BASIL GORDON*

University of California

Los Angeles, California 90024

\section{ASSOCIATE EDITORS}
E. F. BECKENBACH
B. H. NeUmanN
F. WOLF
K. YoSHIDA

\section{SUPPORTING INSTITUTIONS}

UNIVERSITY OF BRITISH COLUMBIA CALIFORNIA INSTITUTE OF TECHNOLOGY

UNIVERSITY OF CALIFORNIA MONTANA STATE UNIVERSITY

UNIVERSITY OF NEVADA

NEW MEXICO STATE UNIVERSITY

OREGON STATE UNIVERSITY

UNIVERSITY OF OREGON

OSAKA UNIVERSITY

UNIVERSITY OF SOUTHERN CALIFORNIA
STANFORD UNIVERSITY

UNIVERSITY OF TOKYO

UNIVERSITY OF UTAH

WASHINGTON STATE UNIVERSITY

UNIVERSITY OF WASHINGTON

AMERICAN MATHEMATICAL SOCIETY CHEVRON RESEARCH CORPORATION TRW SYSTEMS

NAVAL WEAPONS CENTER 


\section{Pacific Journal of Mathematics}

\section{Vol. 32, No. $1 \quad$ January, 1970}

Robert Alexander Adams, Compact Sobolev imbeddings for unbounded domains ........................................ 1

Bernhard Amberg, Groups with maximum conditions .................. 9

Tom M. (Mike) Apostol, Möbius functions of order k............... 21

Stefan Bergman, On an initial value problem in the theory of two-dimensional transonic flow patterns ................... 29

Geoffrey David Downs Creede, Concerning semi-stratifiable spaces ...... 47

Edmond Dale Dixon, Matric polynomials which are higher

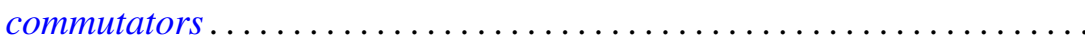

R. L. Duncan, Some continuity properties of the Schnirelmann density.

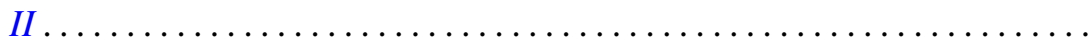

Peter Larkin Duren and Allen Lowell Shields, Coefficient multipliers of $H^{p}$

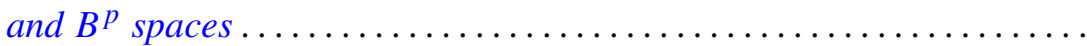

Hector O. Fattorini, On a class of differential equations for vector-valued

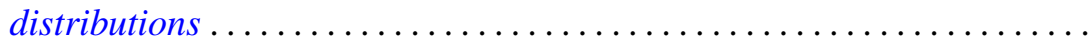

Charles Hallahan, Stability theorems for Lie algebras of derivations. . . . . . 105

Heinz Helfenstein, Local isometries of flat tori ................ 113

Gerald J. Janusz, Some remarks on Clifford's theorem and the Schur

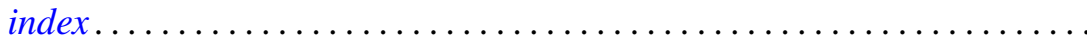

Joe W. Jenkins, Symmetry and nonsymmetry in the group algebras of discrete groups. ...

Herbert Frederick Kreimer, Jr., Outer Galois theory for separable

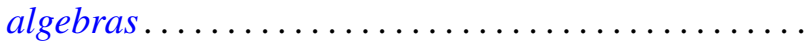

D. G. Larman and P. Mani, On visual hulls

R. Robert Laxton, On groups of linear recurrences. II. Elements of finite order.

Dong Hoon Lee, The adjoint group of Lie groups ...

James B. Lucke, Commutativity in locally compact rings

Charles Harris Scanlon, Rings of functions with certain Lipschitz

$$
\text { properties ............................... }
$$

Binyamin Schwarz, Totally positive differential systems .

James McLean Sloss, The bending of space curves into piecewise helical curves.

James D. Stafney, Analytic interpolation of certain multiplier spaces ...

Patrick Noble Stewart, Semi-simple radical classes.......

Hiroyuki Tachikawa, On left $\mathrm{QF}-3$ rings ...................... 255

Glenn Francis Webb, Product integral representation of time dependent nonlinear evolution equations in Banach spaces.... . . . 